\title{
Responsabilidad de Proteger y el Derecho Internacional de los Refugiados ¿una intersección posible?
}

\author{
Responsibility to Protect and International Refugee Law \\ a possible intersection?
}

\begin{abstract}
IGNACIO ODRIOZOLA
Abogado (UBA). Maestrando en Relaciones Internacionales (UBA). Estudios cursados en Derechos Humanos y Derecho Humanitario (AU/WCL). Abogado en la Comisión del Migrante de la Defensoría General de la Nación (DGN) e investigador en la Red Sudamericana para las Migraciones Ambientales (RESAMA). Correo electrónico: nacho_odriozola@hotmail.com
\end{abstract}

\section{Resumen}

La doctrina de la Responsabilidad de Proteger y el derecho internacional de los refugiados surgieron como reacción por parte de la comunidad internacional: sea en uno $u$ otro contexto, ambos emergieron ante la ausencia o el desinterés de un Estado por brindar protección a sus habitantes. No obstante, a la fecha poco se ha hecho por explorar puntos de contacto entre las dos disciplinas. Por lo tanto, mientras el mundo es testigo de la mayor crisis de desplazamiento forzado de la cual se tiene registro, este artículo propone -intentar- hallar una intersección entre la Responsabilidad de Proteger y el derecho internacional de los refugiados, para verificar si los postulados de la primera pueden asistir o auxiliar al segundo y, así, favorecer a la protección de las personas desplazadas forzadamente como a coadyuvar a que el problema

\section{Abstract}

The doctrine of the Responsibility to Protect and international refugee law, both appeared as a reaction of the international community: in one or another context, they emerged because of State absence or careless in giving protection to their habitants. Nevertheless, very little has been done for exploring spots of contact between both disciplines. So, while the world witnesses the major crisis of forced displaced population ever, the article proposal is -trying- to find intersections between Responsibility to Protect and International Refugee Law, to verify if the postulates of the first can assist the second and, then, contribute to protecting forced displaced people and help the problem of refugees not to become a cause of tension between States or within them. 
Perspectivas Revista de Ciencias Sociales - ISSN 2525-1112 | Año 4 No. 7 Enero-Junio 2019, pp. 99-115

de los refugiados no se convierta en una causa de tensión entre los Estados o hacia adentro de ellos.

Palabras clave

Responsabilidad de Proteger Refugiados - ACNUR - Intersección
Keywords

Responsibility to Protect - Refugees

- UNHCR - Intersection

\section{Introducción}

Immanuel Kant escribió en 1795 "La paz perpetua”, una obra definida en sus propias palabras como una "cláusula salvatoria" que contenía una serie de postulados para superar el estado de naturaleza y alcanzar la paz "entre los hombres que viven juntos". Kant consideró esencial para lograr semejante cometido el desarrollo de la noción de la ciudadanía mundial y la universal hospitalidad. Ambos conceptos, confluían en el derecho a la hospitalidad -en oposición a la hostilidad- que asiste a toda persona extranjera a integrarse en una nueva sociedad sin recibir un trato desfavorable. La razón de ser de este derecho explicó, es "la común posesión de la tierra" y la imposibilidad de las personas de diseminarse hasta el infinito sobre una superficie limitada, supuesto que, a su entender, obliga a la raza humana a tolerarse mutuamente. Kant, sentenció su idea afirmando que nadie tiene mejor derecho que otro a estar en determinado lugar del planeta (Kant, 1795:10).

El derecho a la hospitalidad, en la teoría kantiana, es uno de los medios necesarios para alcanzar la construcción de una "liga de estados naciones soberanos" (Völkerbund) y representa el derecho de todas las personas a la permanencia temporaria en otro estado-nación. Kant explicó que este derecho no podría negarse, y que tal negativa sería insostenible, si de ella pudiese resultar la destrucción o la muerte de la persona. La esencia de la hospitalidad radicará entonces en un deber moral con consecuencias legales potenciales: los Estados receptores de la persona desplazada tienen la obligación de recibirla con base en su pertenencia a la mencionada "liga de estados naciones soberanos" (Benhabib, 2004:4).

Las nociones que Kant presentó en "La paz perpetua" impactaron y se perfeccionaron en el derecho internacional del siglo XX. La idea de crear una institución que expresara la voluntad general de los Estados para asegurar la paz mundial y solucionar los conflictos internacionales, por ejemplo, se refleja con claridad en el preámbulo de la Carta de las Naciones Unidas (Capps, 2004:266). Además, gracias a las Naciones Unidas y a otros espacios de cooperación interestatal, fue posible desarrollar el derecho a la hospitalidad, cristalizado hoy día en un entramado normativo-institucional internacional que protege a las personas refugiadas y a sus derechos.

Sin embargo, como veremos a continuación, este derecho a la hospitalidad se encuentra, sino en jaque, cada vez más restringido y en pugna. 
El mundo actual es testigo de la mayor crisis de desplazamiento forzado jamás presenciada: según el Alto Comisionado de Naciones Unidas para los Refugiados (en adelante, "ACNUR") 68.5 millones de personas han debido abandonar sus hogares como consecuencia de distintos escenarios donde la violencia, la persecución y los efectos del clima, por mencionar algunos factores, prevalece. Del total de personas desplazadas de manera forzada, 25.4 millones son refugiadas (ACNUR, 2018:2).

A partir de estas cifras, ACNUR también ha estipulado cuáles son los Estados que reciben la mayor cantidad de estos flujos concluyendo que resultan ser aquellos que limitan con los países donde reina el conflicto o la persecución. Por caso, los cinco países que han acogido la mayor cantidad de refugiados en 2017 fueron Turquía, que recibió 3.5 millones, Pakistán, 1.4 millones, Uganda, 1.4 millones, Líbano, 998.900 mil y la República Islámica de Irán, 979.400 (ACNUR, 2018:2). En otras palabras, 8.278.300 refugiados, es decir, un tercio de la totalidad, han sido acogidos sólo en cinco Estados de los 193 que pertenecen a la Organización de Naciones Unidas (en adelante, "ONU").

La Convención sobre el Estatuto de los Refugiados de 1951 (en adelante, "Convención" o "Convención del 1951"), reconoce en su preámbulo que "la concesión del derecho de asilo puede resultar excesivamente onerosa para ciertos países" y que "la solución satisfactoria de los problemas cuyo alcance y carácter internacionales han sido reconocidos por la ONU no puede, por esto mismo, lograrse sin solidaridad internacional"1. La recepción de flujos masivos de personas refugiadas, además de representar un serio costo económico para el país que acoge, también puede generar un contexto que atenta contra las obligaciones asumidas por el propio Estado en favor de ellas, significando la potencial vulneración de los derechos humanos de las personas refugiadas que la misma Convención busca proteger.

Sin embargo, a pesar de que la Convención de 1951 toma nota de la importancia de la cooperación internacional en este asunto, lo cierto es que no hay una obligación legal dentro del texto convencional que imponga a otros Estados el deber de compartir los costos asociados a la recepción de refugiados (Ferris, 2016:309-407).

De allí que el catálogo de países antes citados -ninguno europeo- revela una contradicción y ayuda a echar por tierra (cuanto menos) la errónea percepción que coloca a la Unión Europea como única responsable de hacer frente al desafío de recibirlos; desafío que por cierto busca disuadir mediante la prestación económica a países de expulsión o de recepción, a través de la firma de acuerdos bilaterales de dudosa procedencia legal y contradictorios con los principios del Derecho Internacional de los Refugiados (Odriozola, 2016:96-111), o mediante el blindaje de

\footnotetext{
${ }^{1}$ Convención sobre el Estatuto de los Refugiados, Preámbulo, párr. $4^{\circ}$. Adoptada en Ginebra, Suiza, el 28 de julio de 1951 por la Conferencia de Plenipotenciarios sobre el Estatuto de los Refugiados y de los Apátridas (Naciones Unidas), convocada por la Asamblea General en su resolución 429 (V), del 14 de diciembre de 1950. Entrada en vigor: 22 de abril de 1954, de conformidad con el artículo 43.
} 
sus fronteras marítimas, terrestres y aéreas a partir de la implementación del sistema Frontex².

Esta contradicción entre los dichos -digamos, la percepción sobre la solidaridad europea- y los hechos -estadísticas documentadas sobre países de mayor acogida-, cobra más relevancia cuando se advierte que, en los últimos tiempos, uno de los sucesos de mayor preponderancia en materia de derechos humanos se ha dado con la expansión de diferentes expresiones que buscan proteger al ser humano de los excesos de la guerra y los conflictos. En décadas recientes, el esfuerzo de la comunidad internacional, incluida la Unión Europea y sus países, ha transmutado en el desarrollo de normas que protegen grupos específicos, como los niños o los desplazados internos, y ha generado avances significativos en asuntos sobre derecho internacional humanitario, derecho internacional de los derechos humanos y derecho internacional de los refugiados (Ferris, 2016:309-407).

A partir de este esfuerzo por proteger a escala internacional al individuo, emergió la doctrina de Responsabilidad de Proteger (del inglés Responsibility to Protect, en adelante "R2P"), cuyo objetivo, como se desarrollará posteriormente, es proteger a las víctimas de crímenes internacionales: de genocidio, de lesa humanidad, de guerra y de limpieza étnica. Su origen, que se distingue de los principios del derecho internacional humanitario, surgió en respuesta a las tragedias ocurridas en la década de los 90 -por caso, Ruanda y los conflictos balcánicos-, y primordialmente con posterioridad a la intervención humanitaria de la Organización del Tratado del Atlántico Norte (en adelante, "OTAN") en el conflicto de Kosovo.

Las diferencias entre el concepto de R2P y el marco internacional de derechos que asiste a los refugiados, son grandes, disímiles y de antemano podría decirse que no existen razones legales para vincularlas en un mismo texto. No obstante, el presente trabajo intentará trazar una intersección entre ambos campos. Su finalidad, será dilucidar si a pesar de haber surgido en épocas y contextos distintos, la implementación de la doctrina de R2P puede favorecer a la protección de las personas refugiadas y asegurar esa solidaridad interestatal necesaria para evitar que "el problema de los refugiados [...] se convierta en causa de tirantez entre los Estados"3. Por esto, inicialmente se abordará la noción de R2P haciendo foco sobre el contexto que permitió su surgimiento, sus propósitos y principales elementos. Una vez ello, me adentraré en algunos desafíos propios del derecho internacional de los refugiados (en adelante, "DIR") y examinaré si es posible hallar una intersección entre la R2P y el DIR, para que el primero asista o auxilie al segundo cuando este último así lo requiere. Para finalizar, ofreceré unas reflexiones generales sobre el tema desarrollado con la intención de alentar el debate y dejar algunas posibles

\footnotetext{
${ }^{2}$ La Agencia Europea de la Guardia de Fronteras y Costas (Frontex), tiene por finalidad de ayudar a los Estados miembros de la UE y los países asociados al espacio Schengen a gestionar sus fronteras exteriores y contribuye a armonizar los controles fronterizos entre los países de la UE. La Agencia facilita la cooperación entre las autoridades fronterizas de cada país de la UE, ofreciendo apoyo técnico y experiencia. Para mayor desarrollo dirigirse a: http://frontex.europa.eu/

${ }^{3}$ Convención sobre el Estatuto de los Refugiados, Preámbulo, párr. 5.
} 
Perspectivas Revista de Ciencias Sociales - ISSN 2525-1112 | Año 4 No. 7 Enero-Junio 2019, pp. 99-115

iniciativas que, espero, logren promover futuras contribuciones sobre esta (posible) intersección entre la R2P y el DIR.

\section{Responsabilidad de Proteger ¿una respuesta en tiempos de cambio?}

Hacia finales del Siglo XX, se hizo tangible que el concepto de "soberanía estatal" debía ser redefinido. A partir del precitado caso de la OTAN y la intervención humanitaria en Kosovo, comenzó a hacerse notorio que la definición de soberanía había perdido el carácter que le asignaba el Derecho Internacional Público clásico o el paradigma westphaliano de la Carta de Naciones Unidas (Annan, K. 1999:17). Incluso, en el Informe sobre el Milenio el entonces Secretario General de Naciones Unidas, Kofi Annan, recordando que el Consejo de Seguridad se vio paralizado para actuar en los conflictos de Ruanda y de la Ex-Yugoslavia, propuso la siguiente disyuntiva:

Si la intervención humanitaria es, en realidad, un ataque inaceptable a la soberanía, ¿cómo deberíamos responder a situaciones como las de Ruanda o Srebrenica y a las violaciones graves y sistemáticas de los derechos humanos que transgreden los principios de nuestra humanidad común? ${ }^{4}$

En el año 2000, Canadá toma la iniciativa de crear la Comisión Internacional sobre Intervención y Soberanía de los Estados (en inglés ICISS, en adelante "CIISE"), y en diciembre de 2001 la mencionada Comisión presentó el documento "Responsabilidad de Proteger", cuyo objetivo fue justamente encontrar una respuesta a la paradoja planteada por Kofi Annan sobre cómo reaccionar y reconciliar el derecho soberano de los Estados con la necesidad de actuar ante violaciones masivas de derechos humanos (Arredondo, 2012:3-73). El Informe CIISE concluyó que la R2P posee dos importantes innovaciones. Por un lado, que debía redireccionarse el foco desde el "derecho a intervenir" hacia la "obligación de proteger a las víctimas de violaciones serias a los derechos humanos" y, junto con ello, debía garantizarse la prevención, la reacción y la ayuda post bélica. La segunda novedad sugirió que la soberanía per se imponía a los Estados la responsabilidad de proteger a sus ciudadanos frente a la violación de derechos humanos, pero, cuando el Estado no tuviese la voluntad o la capacidad de cumplir con las obligaciones propias de la soberanía "comienza la responsabilidad de la comunidad internacional de actuar en su lugar" (ICISS, 2001:570).

En diciembre de 2004, el Grupo de Alto Nivel de Naciones Unidas formuló este principio doctrinal en un informe sobre las amenazas actuales, los desafíos y el

\footnotetext{
${ }^{4}$ Programa de divulgación sobre el genocidio en Rwanda y las Naciones Unidas, La responsabilidad de proteger: ¿Quién es el responsable de proteger a la población contra las burdas violaciones de los derechos humanos? Disponible http://www.un.org/es/preventgenocide/rwanda/about/bgresponsibility.shtml
} 
Perspectivas Revista de Ciencias Sociales - ISSN 2525-1112 | Año 4 No. 7 Enero-Junio 2019, pp. 99-115

cambio, titulado "Un mundo más seguro: la responsabilidad que compartimos". En él, se indicó que:

Al suscribir la Carta de las Naciones Unidas, los Estados no sólo se benefician de los privilegios de la soberanía (...) también asumen sus responsabilidades (...) la historia nos enseña claramente que no puede darse por sentado que todos los Estados podrán o querrán siempre cumplir las obligaciones que les incumben en relación con su propia población y no causar daño a sus vecinos. $Y$ en tales circunstancias, los principios de la seguridad colectiva significan que parte de esa obligación debe ser asumida por la comunidad internacional, actuando de conformidad con la Carta de las Naciones Unidas y la Declaración Universal de Derechos Humanos (CRIES, 2004).

Un año más tarde, la noción de R2P fue aprobada y reconocida por unanimidad en la Cumbre Mundial de Naciones Unidas de 2005, siendo receptada en los párrafos 138 y 139 del Documento Final (AGNU, 2005:33).

En lo particular, en el párrafo 138 de dicho documento, se indicó que la responsabilidad de proteger a la población de crímenes internacionales de genocidio, de guerra, de depuración étnica y de lesa humanidad, conlleva la prevención mediante la adopción de medidas apropiadas y necesarias. A su vez, se asentó expresamente que los Estados aceptaban dicha obligación y que convenían en obrar en consecuencia.

Seguidamente, el párrafo 139 destacó que la comunidad internacional se comprometía a adoptar medidas colectivas, de manera oportuna y decisiva, por medio del Consejo de Seguridad, y en colaboración con las organizaciones regionales pertinentes cuando proceda, si los medios pacíficos resultaban inadecuados y las autoridades nacionales no protegían a su población. ${ }^{5}$

Meses más tarde, el entonces Secretario General de Naciones Unidas (en adelante "Secretario General" o "SGNU"), Kofi Annan, sostuvo que el mundo debía salir de la era de la legislación para entrar en aquella de la implementación y, para lograr esto, los Estados debían comenzar por aplicar todos aquellos instrumentos a los que se obligaron, incluida la Responsabilidad de Proteger (SGNU, 2005:35).

Siguiendo esta línea, en el año 2006, el Consejo de Seguridad dictó la Resolución No 1674 donde expresamente reafirmó los párrafos 138 y 139 del precitado Documento Final, y la necesaria responsabilidad de los Estados de resguardar a su población de crímenes atroces (CSNU, 2006:2).

Con este último aval parecía, entonces, que el concepto de R2P se había consolidado en poco tiempo como una nueva herramienta con la cual contaban los Estados para disuadir o evitar los crímenes de mayor trascendencia para la comunidad internacional. Sin embargo, como veremos a continuación, sería otro ex Secretario

\footnotetext{
${ }^{5}$ Documento Final de la Cumbre Mundial (2005), Reunión Plenaria de Alto Nivel, 14-16 de septiembre, Naciones Unidas, Nueva York, párr. 138-139
} 
Perspectivas Revista de Ciencias Sociales - ISSN 2525-1112 | Año 4 No. 7 Enero-Junio 2019, pp. 99-115

General, Ban Ki-Moon, el encargado de dotar a este instituto invertebrado de ciertas precisiones que alentarían su operatividad, incluyendo entre ellas diversas referencias a las personas refugiadas.

\section{Hacer efectiva la Responsabilidad de Proteger ¿a las personas refugiadas?}

Hacia el año 2009, en el informe de seguimiento a la Cumbre Mundial de 2005, presentado ante la Asamblea General y titulado "Hacer efectiva la responsabilidad de proteger" (SGNU, 2009:12-28), Ban Ki-moon realizó los aportes de mayor jerarquía sobre R2P al proponer que la misma debería contar con tres fases: protección del propio Estado, asistencia de terceros Estados $y$, finalmente, de la comunidad internacional. También, incluyó en su informe las tres dimensiones o pilares de la responsabilidad: de prevenir, de reaccionar y de reconstruir. Además, destacó las ideas de "capacidad de alerta temprana" para detectar la potencial comisión de crímenes o la inacción del Estado frente a ellos y "la necesidad (de la comunidad internacional) de brindar respuestas colectivas y decisivas" frente a estas situaciones (Arredondo, 2012:3-73).

Con relación a las fases precitadas, y particularmente a la primera, que obedece a la responsabilidad de proteger del Estado, Ban Ki-moon indicó que cuando la población de un país se encuentra en peligro, es este Estado aquél que tiene la responsabilidad principal de protegerla frente a la instigación y la comisión de crímenes atroces. Entre los mecanismos para garantizar este objetivo, resaltó la necesidad de formar parte de ciertos tratados internacionales, entre los que incluyó "el derecho de los refugiados" (Arredondo, 2012:3-73).

Con relación a la segunda fase, sobre asistencia de terceros Estados y formación de capacidad, Ban Ki-moon indicó que ante la falta de capacidad o control territorial del Estado afectado, si este no puede o no quiere proporcionar dicha protección, corresponderá a terceros Estados asistirle pero, también, a ciertas agencias de Naciones Unidas, entre las que mencionó -y reconoció- el trabajo del ACNUR, que al garantizar asilo y protección a refugiados ha "beneficiado numerosas víctimas potenciales de crímenes o actos relativos a la responsabilidad de proteger" (Arredondo, 2012:3-73).

Por último, si las medidas de asistencia de los terceros Estados son ineficaces debido a la falta de disposición de la clase dirigente nacional o la existencia de graves problemas de capacidad operativa, la responsabilidad será trasladada a la comunidad internacional, que deberá adoptar medidas rápidas y eficaces, configurando así el tercer estadio. Este último podría incluir, en circunstancias excepcionales, la intervención armada (Olásolo Alonso, 2012:80-81). En esta última fase, a criterio de Ban Ki-Moon, las Naciones Unidas y sus diferentes agencias "[tienen una] importancia crítica" pero, aclaró, que su rol y compromiso tendría "mucha más eficacia si los objetivos relativos a la responsabilidad de proteger, entre ellos la protección de los refugiados y los desplazados internos, pasaran a formar parte de sus prioridades" (SGNU, 2009:12-28). 
Ahora bien, en el informe en cuestión Ban Ki-Moon también hizo hincapié en que esta noción difiere -aunque no la rechace- del concepto de intervención humanitaria. En efecto, como adelantamos, hizo referencia a las tres dimensiones o pilares que posee la R2P: de prevenir, de reaccionar y de reconstruir. Todas ellas, apuntan a fomentar la implementación de vías alternativas a la fuerza armada para solucionar un conflicto, tal como lo señala el párrafo 139 del Documento Final al indicar que la comunidad internacional, mediando las Naciones Unidas, tiene también la responsabilidad de utilizar vías diplomáticas, humanitarias y otros medios pacíficos apropiados de conformidad con los Capítulos VI y VIII de la Carta (Díaz Barrado, 2012:9-10).

En este sentido, el SGNU identificó a la Responsabilidad de Prevenir como fundamental, en tanto aquí se inscribe la capacidad de alerta temprana, junto con la posibilidad de adoptar una amplia gama de medidas que no implican el uso de la fuerza y que podrían, y deberían, ser utilizadas como factor persuasivo o disuasivo para evitar el desarrollo de un conflicto. Estas incluyen, entre otras, sanciones económicas, políticas o diplomáticas, acciones legales o judiciales, entre otras (Arredondo, 2012:3-73). Con posterioridad me referiré en concreto a esta dimensión. Por su parte, la Responsabilidad de Reaccionar, significa responder frente a situaciones donde la apremiante necesidad humana impone la obligación de adoptar medidas adecuadas y efectivas, que pueden incluir medidas coercitivas como sanciones y persecuciones internacionales $y$, en casos extremos, permiten la intervención militar (Stamnes, 2008).

Por último, sobre la Responsabilidad de Reconstruir se destacó que debe proveerse asistencia para la recuperación del Estado afectado y, entre diversas medidas, deben garantizarse medios para su reconstrucción material, un acompañamiento en lo atinente a la justicia transicional en conjunto con la reconciliación interna de los actores sociales y, a su vez, debe atenderse a las razones que impulsaron lo ocurrido (Sarkin, 2012:31).

De lo expuesto, en el informe "Hacer efectiva la Responsabilidad de Proteger" se advierte que la referencia a las personas refugiados es marginal pero no por eso menos importante. El ex Secretario General se refirió a ellos con especial énfasis en la tercera fase, la fase más distintiva de la R2P, donde será la comunidad internacional en su conjunto deberá tomar cartas en el asunto para remediar una situación donde el potencial de crímenes internacionales es tan serio como la necesidad de proteger a las personas desplazadas por esta amenaza.

Los elementos desarrollados en este punto nos brindan un marco conceptual pero tangible que, ahora sí, nos permitirá examinar si pueden la R2P y el DIR hallar puntos de contacto que hagan del primero, una rueda de auxilio o de apoyo al segundo.

\section{Interrelación entre R2P y el derecho internacional de los refugiados}

El impacto social y la desestabilización política ocasionada por el arribo de un extenso número de refugiados que, en 1917, abandonó Rusia y su naciente revolución, representó el primer paso para el desarrollo del derecho internacional de los refugiados y el sistema que hoy día lo conforma. Este sistema, justamente, se expandió 
con el tiempo y de momento su universo se encuentra conformado por la Convención de 1951, el ACNUR y cientos de leyes y políticas domésticas que adecuan la legislación internacional a la nacional (Ferris, 2016:309-407).

Por su parte, como hemos visto, la R2P estuvo incentivada por el profundo deseo de la comunidad internacional de responder de manera efectiva y suficiente ante situaciones donde primaba el sufrimiento humano producto de los crímenes más serios contra la humanidad, pero también con el objetivo de incrementar la estabilidad y la paz internacional.

De allí que, autores como Elizabeth Ferris, concluyen que tanto para la protección de los refugiados como para R2P, existió una convergencia de intereses desde sus respectivos orígenes. Esta convergencia, está basada en la adopción de medidas para aliviar el sufrimiento humano que, a su vez, permite a la comunidad internacional responder ante las crisis de modo tal que los efectos colaterales pudiesen ser minimizados (Ferris, 2016:309-407).

De hecho, en el informe CIISE se menciona a los refugiados. Allí, se destacó la necesidad de los Estados en comprometerse en la prevención de conflictos, toda vez que resulta el modo más certero de evitar flujos de desplazados forzados que salen o abandonan sus respectivos países. También, el informe CIISE resaltó la dificultad de garantizar el retorno de estas personas a sus países de origen en la etapa de post conflicto (ICISS, 2001).

A diferencia de los esfuerzos por hallar conexiones entre la R2P y la protección de las personas desplazadas internamente (ECOSOC, 1998) ${ }^{6}$, poco se ha hecho por explorar la interrelación entre R2P y la protección de refugiados. Probablemente la razón de esto radica en que la protección de refugiados se ha asociado tradicionalmente a un asunto legal y a una obligación impuesta por la Convención de 1951. De hecho, comúnmente la ONU o ACNUR no se refieren a la "responsabilidad" de proteger a los refugiados sino más bien al "deber" de protegerlos. Asimismo, esta postura puede fortalecerse cuando se considera que la precitada Convención, únicamente menciona el término "responsabilidad" o "responsable" en dos ocasiones -una ligada a la familia y otra al ejercicio de la profesión liberal-. Ello, ha hecho que se pierda de vista un elemento común detrás de esta problemática: la necesidad de fomentar el esfuerzo de los Estados de asistirse entre ellos (SGNU, 2009:12-28). En rigor, la palabra "responsabilidad" tiene un alcance distinto en cada una de estas doctrinas: en el contexto de R2P suele considerársela una "obligación moral" o un "deber", mientras que, en relación con la protección y asistencia a los refugiados, se la asocia con el término "carga" (Ferris, 2016:309-407). Más adelante, ahondaré en este aspecto.

Antes bien, una breve mención a un parámetro que nos permitirá acercarnos a la posible- interrelación entre R2P y el derecho internacional de los refugiados: el

\footnotetext{
${ }^{6}$ Vale traer a colación que ambas temáticas "compartieron agenda" en el mismo período (finales de Siglo XX) y recibieron el aval de la comunidad internacional en la mencionada Cumbre Mundial de 2005. Asimismo, los dos campos están conceptualmente ligados a la noción de "soberanía como responsabilidad" y se justifican en términos de paz y seguridad internacional. Además, ambos se apoyan en documentos que no son jurídicamente vinculantes.
} 
indicador de desplazamiento forzado de personas. EI número de personas desplazadas de manera forzada, que arriban a otro Estado o que se movilizan dentro del mismo, puede actuar como indicador para que la comunidad internacional denote la potencialidad de que una serie de incidentes se torne en un conflicto armado. De hecho, los testimonios de personas que huyen por un temor fundado de persecución son una forma práctica para identificar cuándo estos incidentes o un eventual conflicto pueden evolucionar hacia un genocidio o crímenes de lesa humanidad, sirviendo como medios de prueba para activar responsablemente la implementación de estos dos mecanismos de protección (Rimmer, 2010:7-32).

Más allá de este comentario, el lugar donde principalmente se habla de "responsabilidad" con relación a la protección de las personas refugiadas suele ser en los debates relativos a la "responsabilidad compartida", un asunto en agenda desde su abordaje en la Cumbre de Naciones Unidas sobre Refugiados y Migrantes de septiembre de 2016. En este encuentro, los Estados asentaron sus compromisos en la Declaración de Nueva York para los Refugiados y Migrantes, donde además de reconocer la importancia de la cooperación internacional en este asunto, se comprometieron "a repartir más equitativamente la carga y la responsabilidad de acoger y dar apoyo a los refugiados del mundo" (AGNU, 2016:14).

En el contexto de los refugiados, la "repartición de la carga" como suele denominarse a este concepto, es el principio por medio del cual los diversos costos que afronta el Estado receptor al garantizar asilo a las personas que huyen de su país de origen o de residencia habitual, son divididos entre un número mayor de Estados (Milner, 2016:2-8).

Como mencioné en la introducción a este artículo, no existe ninguna imposición legal en los instrumentos vigentes respecto de la obligación de los Estados de compartir los costos asociados a la recepción de los refugiados. Incluso, en el marco de las negociaciones de la Convención de 1951, el entonces Secretario General, Trygve Lie, habría propuesto la inclusión de un artículo relacionado con esta idea en el que se indicaría que, en la medida de sus posibilidades, los Estados deben alivianar la carga acordando recibir a cierto número de refugiados en su territorio (Goodwin-Gill, 2016:9). Tal propuesta, sabemos, fue rechazada.

Sin embargo, a pesar de no haber sido incluida en la Convención de 1951, existen precedentes legales sobre la materia bajo estudio. Entre ellos, puede mencionarse la Convención de la Organización de la Unión Africana (OUA) por la que se regulan los aspectos específicos de problemas de los Refugiados en África de 1969. Precisamente, en su artículo 2.4 la Convención africana indica que, cuando un Estado tenga inconvenientes en conceder asilo, "los demás Estados miembros, con espíritu de solidaridad africana y de cooperación internacional, adoptarán las medidas apropiadas para aliviar la carga de dicho Estado miembro concediendo ellos mismos el derecho de asilo" (Convención de la OUA. 1969). De igual manera, el Consejo de la Unión Europea, en 1995 dictó la Resolución 95/C 262/01, instrumento en el cual estableció que los países miembros de la UE debían promover "un reparto equilibrado y solidario de las cargas relativas a la acogida y estancia temporal de las personas desplazadas en caso de crisis" (CUE, 1995). Asimismo, en 2001 se firmó la 
Declaración de los Estados Parte de la Convención de 1951 y el Protocolo de 1967, estableciendo -una vez más- que la protección a los refugiados "se refuerza con la solidaridad internacional que involucra a todos los miembros de la comunidad internacional y [...] el régimen de protección de refugiados se potencia mediante una cooperación internacional comprometida, en un espíritu solidario y con repartición de la carga entre todos los Estados" (Milner, 2016:2-8). Del mismo modo, y más reciente en el tiempo, se expidieron diversos expertos de Naciones Unidas y de las américas en materia de migraciones, al indicar que los refugiados "son una responsabilidad compartida que requieren respuestas internacionales", pero también, que los Estados deben:

Adoptar medidas dirigidas a garantizar el apoyo internacional y la responsabilidad compartida en el rescate, recepción y alojamiento en casos de grandes movimientos migratorios internacionales. En este sentido, los Estados deben establecer mecanismos internacionales de múltiples partes interesadas para fortalecer y coordinar operaciones [...]. ${ }^{7}$

Por otra parte, cuando se aborda este asunto surge inevitablemente el interrogante de cómo repartir la carga y, así, compartir la responsabilidad de dar acogida, equitativamente, a las personas refugiados. Sobre ello, han surgido algunas propuestas como las de James Hathaway, quien afirma que los Estados tienen "responsabilidades comunes pero diferenciadas" y sugiere que el reparto de la carga se administre más eficazmente en el contexto de las responsabilidades prenegociadas. Asimismo, Peter Schuck ofreció una solución diferente basada en el compromiso de un grupo básico e inicial de Estados que se obliguen a compartir la carga de proteger a las personas refugiadas "proporcionalmente", para que luego los Estados participantes -entre ellos- puedan "negociar sus cuotas pagando a otros para cumplir con sus obligaciones". Ambas ideas no han sido ajenas a críticas, en tanto parecen considerar a los refugiados como mercancía y modifican la idea de repartir la carga por la de "cambio de carga" (Ferris, 2016:309-407). Otra postura, tal vez pretenciosa en términos políticos, aunque razonable en un sentido práctico, propone que los Estados responsables de provocar internamente los flujos de refugiados asuman la carga de su cuidado. Según los autores de esta idea, la misma data de 1939, pero en la actualidad se ha tornado relevante y sugieren que "los países que expulsan a las personas de sus hogares deben pagar los costos de proporcionarles una vida digna". Para lograr este objetivo, proponen que los Estados receptores de refugiados o las instituciones internacionales competentes utilicen los activos de los países de origen de los refugiados (Goodwin-Gill / Sazak, 2015).

Por fuera de estas iniciativas, que apuntan a fomentar el debate y a encontrar soluciones duraderas en materia de protección de refugiados, en las discusiones

\footnotetext{
${ }^{7}$ Declaración conjunta de expertas y expertos de las Naciones Unidas y regionales de cara al Pacto Mundial para una Migración Segura, Ordenada y Legal a la luz de la cumbre en Puerto Vallarta, Comunicado de prensa 203/17, 6 de diciembre de 2017.
} 
relativas a repartir la carga suele identificarse al reasentamiento como una de las formas concretas para compartir la responsabilidad y fortalecer la institución del asilo. ${ }^{8}$ De hecho, al menos bajo la noción de reasentamiento, parece haber un apoyo importante de parte de los Estados para repartir la carga. En este sentido, según cifras de ACNUR de 2015, los Estados Unidos (82 mil), Canadá (22 mil) y Australia (9 mil), han sido quienes más contribuyeron a aceptar personas reasentadas (ACNUR, 2016:57). Aun así, debe mencionarse que muchos de estos Estados se han resistido a acuerdos más formales respecto del reparto de la carga y particularmente se han opuesto a la introducción de nuevas obligaciones, teniendo en sus manos la decisión respecto del cupo de personas que aceptarán. Como concluye Milner, "la práctica de la solidaridad internacional y la repartición de la carga sigue siendo profundamente política con las divisiones Norte-Sur" (Milner, 2016:2-8).

Teniendo en miras ello, y considerando que en los últimos años se han superado todos los récords en materia de desplazados forzados, se ha tornado imperioso asumir que es momento de fortalecer el marco normativo para repartir la responsabilidad respecto de la acogida de personas desplazadas forzadamente. De allí que medidas de esta índole surgen como un avance lógico y acorde con los postulados del derecho internacional de los refugiados.

En efecto, así lo reconoció Antonio Guterres, entonces Alto Comisionado de ACNUR, quien además de indicar que la institución del asilo debe permanecer sacrosanta por ser la máxima expresión de humanidad, sugirió que el mejor camino para lograr esta finalidad es mediante la cooperación internacional y la equilibrada repartición de responsabilidad. Para ello, señaló que el próximo paso debe ser la concreción de un protocolo sobre esta materia (ACNUR, 2015:1). En este contexto, la propuesta de instrumentar un mecanismo para compartir la responsabilidad parece acertado. Razonablemente, ayudará a alivianar las tensiones entre los Estados y permitiría negociar acuerdos entre pares, definir el momento para implementarlos, la articulación de medidas a ser adoptadas y establecer parámetros para precisar cuánto puede contribuir un Estado en función de su capacidad para -eventualmente- recibir apoyo (Türk, 2016:48). A ello, debe agregarse que la idea de este protocolo complementaría a la Convención de 1951, ampliando el espectro de derechos destinados a proteger a los refugiados.

Un punto de partida para fomentar y argumentar en favor de esta propuesta, justamente, puede hallarse en la doctrina de R2P.

Señalé anteriormente que esta noción persigue el fin moral de poner coto al sufrimiento humano, pero, también, el objetivo de incrementar la estabilidad y la paz internacional. Entre los medios con que cuenta esta doctrina, me referí a la

\footnotetext{
${ }^{8}$ Conforme el ACNUR, el reasentamiento consiste en el traslado de refugiados de un país de asilo a otro país que ha acordado admitirles y otorgarles residencia permanente. ACNUR tiene el mandato, de acuerdo con su Estatuto y la Resolución de la Asamblea General de la ONU, de contemplar el reasentamiento como una de sus tres soluciones duraderas. El reasentamiento es único, ya que es la única solución duradera que implica la reubicación de refugiados de un país de asilo a un tercer país. Para más información, acceder a: http://www.acnur.org/que-hace/solucionesduraderas/reasentamiento/
} 
Perspectivas Revista de Ciencias Sociales - ISSN 2525-1112 | Año 4 No. 7 Enero-Junio 2019, pp. 99-115

Responsabilidad de Prevenir como una dimensión o pilar sustancial que apunta a evitar tensiones que puedan derivar en un conflicto armado, sea interno o internacional, o en otra clase de agresiones que puedan generar las condiciones propicias para la comisión de crímenes internacionales.

El arribo de refugiados o solicitantes de asilo indudablemente genera tensiones puertas hacia adentro de los Estados y sobre esto sobran ejemplos: el caso de Suecia $^{9}$, Alemania ${ }^{10}$ o Francia $^{11}$ (por mencionar algunos casos recientes), pero también genera fricciones entre Estados, siendo una demostración de ello el constante forcejeo por "la cuota de ingresantes al espacio Schengen" entre la Unión Europea y Turquía ${ }^{12}$ o entre El Líbano y Jordania. ${ }^{13}$

Las crispaciones políticas y sociales no son causadas por las personas desplazadas forzadamente, sino más bien por los costos que ello insume al Estado, ya sea por acción -establecer condiciones para favorecer el arribo e inclusión de refugiados en la sociedad y así garantizas soluciones duraderas- o por omisión -no disponer de políticas públicas sobre el asunto y "librar a su suerte" a estas personas que recibieron la condición de refugiados o que están a la espera de ella, provocando potenciales tensiones entre estos y personas nacionales-. Desde ya, este análisis sucinto no basta para brindar un panorama acabado de las implicancias políticas, sociales y económicas que trae consigo la gobernabilidad de las migraciones. No obstante, sirve como base para avizorar que las tensiones en cuestión pueden escalar y sembrar un escenario que pueda atentar a futuro contra la paz y la seguridad internacional.

En este contexto, la Responsabilidad de Prevenir puede tener un rol fundamental para lograr evitar escaladas de violencia entre Estados o hacia dentro como resulta de la recepción de personas refugiadas.

Como solución a estas tensiones, fomentar un enfoque preventivo antes que reactivo resulta más lógico cuando se tiene en cuenta que, como contracara, puede implementarse la amenaza para intervenir o determinadas acciones decisivas que pueden implicar el uso de la fuerza. Susan Harris Rimmer sostiene, en este mismo sentido, que las actividades de prevención deben construirse sobre las excepciones a la soberanía ya aceptadas por todos los Estados, entre las que menciona a los derechos humanos (Rimmer, 2010:7-32).

\footnotetext{
${ }^{9}$ CNN Español, Las tensiones en Suecia disminuyen el orgullo por la política de refugiados en ese país, 23 de febrero de 2017. Disponible en: https://cnnespanol.cnn.com/2017/02/23/las-tensiones-en-sueciadisminuyen-el-orgullo-por-la-politica-de-refugiados-en-ese-pais/

${ }^{10}$ Clarín, Crece la tensión en Alemania entre Merkel y sus aliados por la política migratoria, 1 de junio de 2018. Disponible en: https://www.clarin.com/mundo/crece-tension-alemania-merkel-aliados-politicamigratoria_0_SJaxhplG7.html

11 ABC, Macron descarta la creación de campos de refugiados en Francia, 29 de junio de 2018. Disponible en: https://www.abc.es/internacional/abci-macron-descarta-creacion-campos-refugiadosfrancia-201806292041_noticia.html

${ }_{12}$ Hispan TV, Tensiones UE-Turquía: Ankara revaluará acuerdo sobre refugiados, 14 de marzo de 2017. Disponible en: https://www.hispantv.com/noticias/turquia/335765/tensiones-acuerdo-refugiadosankara-union-europea-celik

${ }^{13}$ Washington Institute, Why Refugee Influx Threatens Lebanon, Jordan Stability, 10 de abril de 2014. Disponible en: https://www.washingtoninstitute.org/policy-analysis/view/why-refugee-influx-threatenslebanon-jordan-stability
} 
De esta forma, en base al aspecto preventivo de la R2P, podrían fortalecerse los canales tendientes a generar las condiciones para avanzar hacia la instrumentación de la responsabilidad compartida de la carga: precisar cuánto, cómo y qué responsabilidad tiene cada Estado, alivianaría definitivamente el peso de aquellos países que reciben la mayor proporción de afluentes de refugiados.

También, la asistencia internacional y la formación de capacidad, que representa la segunda fase del R2P, junto con la ayuda de la comunidad internacional, serán trascendentales para sumar actores estatales, no estatales y organismos internacionales y regionales que apoyen la moción. Ello, además, deberá estar acompañado lógicamente de consensos, de mecanismos claros relativos al mantenimiento del asilo, el apoyo a los países "saturados", el establecimiento de modos sobre cómo compartir la carga de manera predecible y efectiva, junto con mecanismos para prevenir la desestabilización (Ferris, 2016:309-407).

Todos estos factores conjugados podrían permitir avanzar en el establecimiento de un instrumento que prevea pautas precisas y acciones positivas respecto de cómo compartir la responsabilidad entre Estados para brindar protección equitativamente a las personas refugiadas y desplazadas, en miras a prevenir escaladas de violencia y evitar tensión interestatales o intraestatales que puedan derivar en conflictos o en agresiones.

\section{Conclusión}

Desde su implementación en el conflicto de Libia, en 2011, no puede negarse que la R2P ha perdido vigencia y legitimidad. En dicha ocasión, bajo la doctrina de R2P, se favoreció la intervención militar de la OTAN en el país africano con el objetivo de poner freno a los embates del ejército libio contra la población civil. Ello, al margen de significar la caída de Muammar Gaddafi, no se tradujo en el cese de la violencia hacia la población. Por el contrario, potenció la atomización del país y el surgimiento de grupos militares con diversas pretensiones, situación que drenó en un conflicto que alcanza a estos días. No hubo, de parte de la comunidad internacional, un interés por aplicar la R2P en su faz de prevención ni de reconstrucción y, a partir de esto, sumado a la retórica política que circundó -y criticó- la intervención militar, se creó un aura de desconfianza con relación a la continuidad de su implementación.

Aun así, no puede perderse de vista los encomiables fines que persigue esta doctrina, como tampoco puede obviarse que su creación y desarrollo, a los ojos del derecho internacional, son sumamente recientes. Así, la R2P avanza hacia su próxima década. Necesitará, para consolidar su progreso, superar los obstáculos y los desafíos emergentes que enfrenta la comunidad internacional respecto de la prevención de atrocidades; todo esto, en un contexto global en el cual se ha reinstalado la visión estato-céntrica, la celosía por la soberanía y la susceptibilidad respecto de la injerencia en los asuntos internos de terceros Estados.

Para alentar el uso de los elementos de la R2P y garantizar su continuidad, una alternativa interesante será centrarse en incorporarlos en otras áreas del derecho donde su utilidad sería optimizada y bien receptada. 
Perspectivas Revista de Ciencias Sociales - ISSN 2525-1112 | Año 4 No. 7 Enero-Junio 2019, pp. 99-115

Un punto de conexión entre la R2P y el DIR, como he desarrollado en este trabajo, puede evidenciarse en el pilar de la Responsabilidad de Prevenir, que puede redundar en torno a una equitativa distribución de la carga y de la responsabilidad compartida de los Estados respecto de las personas refugiadas que deben abandonar su país de origen o de residencia habitual.

La instrumentación de esta propuesta, de seguro, podrá coadyuvar a prevenir escaladas de violencia y crispaciones evitables entre Estados o puertas adentro de ellos, permitirá brindar previsibilidad y con ello una mejor gestión de la política migratoria. En definitiva, ayudará a brindar protección real a las personas desplazadas con base en principios reconocidos por la comunidad internacional como la solidaridad, la cooperación internacional y la asistencia humanitaria.

No parecería muy desatinado suponer la posibilidad de que esta instrumentación, a futuro, se concrete. El respaldo que ha recibido el reciente Pacto Mundial de Refugiados y la inclusión de la distribución de la carga y de la responsabilidad compartida en dicho documento, aún a pesar de no tener carácter vinculante, reflejan la voluntad política internacional, demuestran que los foros multilaterales y la búsqueda de respuestas conjuntas cuentan todavía con apoyo y adhesión mayoritaria, y ratifican la condición de estos espacios como canales necesarios para la búsqueda de soluciones duraderas.

De ocurrir esto, puede que comencemos una nueva etapa. Una etapa con menos muros, menos medidas de securitización y fronteras que dividen; una etapa más cercana a las aspiraciones de Kant, donde se efectivice el anhelado derecho a la hospitalidad como medio para alcanzar un fin ambicioso, pero, por qué no, posible: la paz perpetua.

Recibido: 22/03/2019

Aceptado: 08/06/2019

\section{Referencias bibliográficas}

ACNUR (2016), Projected Global Resettlement Needs 2017, 22nd Annual Tripartite Consultations on Resettlement, Geneva: 13-15 June 2016, pág. 57. Fecha de consulta: 15 de diciembre de 2018. Disponible en: http://www.unhcr.org/protection/resettlement/575836267/unhcr-projected-globalresettlement-needs-2017.html

ACNUR, (2015) Opening remarks at the 66th session of the Executive Committee of the High Commissioner's Programme. António Guterres, United Nations High Commissioner for Refugees. Geneva, 5 de octubre de 2015. Fecha de consulta: 15 de diciembre de 2018.2 Disponible en: http://www.unhcr.org/admin/hcspeeches/56122bd76/opening-remarks-66th-sessionexecutive-committee-high-commissioners-programme.html 
Perspectivas Revista de Ciencias Sociales - ISSN 2525-1112 | Año 4 No. 7 Enero-Junio 2019, pp. 99-115

ACNUR, (2018), Tendencias Globales. Desplazamiento forzado en 2017, pág. 2. Fecha de consulta: 15 de diciembre de 2018. Fecha de consulta: 18 de diciembre de 2018. Disponible en: https://www.acnur.org/5b2956a04.pdf

AGNU - Asamblea General de Naciones Unidas (2016), Declaración de Nueva York para los Refugiados y los Migrantes, A/71/L.1, Párr. 68, pág. 14.

AGNU - Asamblea General de Naciones Unidas, Resoluciòn N60/1, 24 de octubre de 2005, UN Doc A/Res/60/1, Párr. 138-139, pág. 33.

ANNAN, K. (1999), "Two concepts of Sovereingty”, The Economist, Nueva York, pág. 17.

ARREDONDO, R. (2012), Intervención Humanitaria y Responsabilidad de Proteger: ¿hacia un nuevo paradigma de protección de los derechos humanos?, Ed. ISEN, Buenos Aires, pp. 3 - 73

BENHABIB, S. (2004), "Sobre la hospitalidad: una relectura del derecho cosmopolita de Kant", Los derechos de los otros. Extranjeros, residentes y ciudadanos. Gedisa Editora, Barcelona, pp. 4-5.

CAPPS, P. (2004), "El proyecto kantiano en la teoría legal internacional moderna", Homenaje a Kant, Estudios Socio-Jurídicos, Vol. 1, No. 1, Bogotá, p. 266.

Convención de la OUA por la que se regulan los aspectos específicos de problemas de los Refugiados en África, art. 2.4, aprobada por la Asamblea de Jefes de Estado y de Gobierno en su sexto período ordinario de sesiones, Addis Abeba, 10 de setiembre de 1969 y entrada en vigor el 20 de junio de 1974.

Convención sobre el Estatuto de los Refugiados 1951

CRIES - Coordinadora Regional de Investigaciones Económicas y Sociales, Informe del Grupo de Alto Nivel sobre las amenazas, los desafíos y el cambio: Un mundo más seguro: la responsabilidad que compartimos, 17 de diciembre 2004. Fecha de consulta: 19 de diciembre de 2018. Disponible en: http://www.cries.org/wpcontent/uploads/2015/09/pp41-web-FINAL-Corr.pdf

CSNU - Consejo de Seguridad de Naciones Unidas, Resolución 1674 (2006), S/RES/1674, del 28 de abril 2006, Párr. 4, pág. 2.

CUE - Resolución del Consejo de la Unión Europea del 25 de septiembre de 1995 sobre el reparto de cargas en relación con la acogida y la estancia, con carácter temporal, de las personas desplazadas, art. 4.

DÍAZ BARRADO, C.M. (2012), La Responsabilidad de Proteger en el Derecho Internacional Contemporáneo: entre lo conceptual y la práctica internacional, Buenos Aires, Pp. 9-10. Fecha de consulta: 18 de diciembre de 2018. Disponible en www.reei.org

ECOSOC - Consejo Económico y Social, Principios Rectores de los desplazamientos internos, W/CN.4/1998/53/Add.2*, 11 de febrero de 1998.

FERRIS, E. (2016), "International Responsibility, Protection and Displacement: Exploring the Connections between R2P, Refugees and Internally Displaced Persons", Global Responsibility to Protect, Ed. Brill Nijhoff, p. 309-407.

GOODWIN-GILL, G.S. \& SAZAK (2015), "Footing the Bill: Refugee-Creating States' Responsibility to Pay", Foreign Affairs. Fecha de consulta: 17 de diciembre de 2018. Disponible en: https://www.foreignaffairs.com/articles/africa/2015-07-29/footing-bill 
Perspectivas Revista de Ciencias Sociales - ISSN 2525-1112 | Año 4 No. 7 Enero-Junio 2019, pp. 99-115

GOODWIN-GILL, G.S. (2016), "The movement of people between States in the 21th century - an agenda for urgent institutional change", Artículo presentado en el Foro "La crisis global de las migraciones: sus desafíos para Estados Unidos, Europa y el orden mundial", p. 9.

ICISS - International Commission of Intervention and State Sovereignty (2001), The Responsibility to Protect, International Development Research Centre, Ottawa, pp. 570.

KANT, I. (1795), La paz perpetua, Ed. Biblioteca Virtual Universal, pág. 10. Fecha de consulta: 11 de diciembre de 2018. Disponible en: http://www.biblioteca.org.ar/libros/89929.pdf

MILNER, J. (2016), "When norms are not enough: understanding the principle and practice of burden and responsibility sharing for refugees", CIGI Policy Brief, pp. 2-8 NASI, H. (2009) "Operationalizing the Responsibility to Protect and Conflict Prevention: dilemmas of civilian protection in armed conflict", I Journal of Conflict and Security Law.

ODRIOZOLA, I., (2016), "El lado oculto del Acuerdo UE-Turquía. Una mirada crítica desde la perspectiva del Derecho Internacional de los Refugiados", Revista Perspectiva en Ciencias Sociales, Ed. No. 2 Julio-Diciembre, Rosario, pp. 96-111. Fecha de consulta: 12 de diciembre de 2018. Disponible en: https://rephip.unr.edu.ar/handle/2133/6850

OIM, Pacto Mundial sobre Migración. Fecha de consulta: 17 de diciembre de 2018. Disponible en: http://rosanjose.iom.int/site/sites/default/files/Pacto\%20mundial\%20sobre\%20migraci on.pdf

OLÁSOLO ALONSO, H. (2012), “La Función de la Corte Penal Internacional en la Prevención de delitos", Derecho Penal Internacional, Ed. Rubinzal-Culzoni, Santa Fe, pp. 80-81.

RIMMER, S.H. (2010), Refugees, Internally displaced persons and the 'responsibility to protect', Research Paper No. 185, ACNUR, pp. 7 - 32.

SARKIN, J. (2012) Is the responsability to Project an accepted norm of International law in the post-libya era? How its third pillar ought to be applied?, Groningen Journal of International Law, Vol. 1, No. 0, p. 31.

SGNU - Secretario General de Naciones Unidas (2009), Informe del Secretario General Ban Ki-Moon, Hacer efectiva la responsabilidad de proteger. A/63/677, párr. 18-68, pp. 12-28 Fecha de consulta: 18 de diciembre de 2018. Disponible en: http://www.un.org/en/events/pastevents/pdfs/larger_freedom_exec_summary.pdf

SGNU - Secretario General de Naciones Unidas, (2005) Report of the SecretaryGeneral, Annan, K. In Larger Freedom: Towards Development, Security, and Human Rights for All" UN Doc A/59/2005, Párr. 132, pág. 35.

STAMNES, E. (2008) Operationalizing the Preventive Aspects of the Responsibility to Protect, Norwegian Institute of International Affairs. Fecha de consulta: 19 de diciembre de 2019. Disponible en: w.nupi.no/content/download/8501/85020/version/3/file/R2P-1Stam.pdf

TÜRK, V. (2016), "Prospects for Responsibility Share in the Refugee Context", Journal on Migration and Human Security, Volume 4, Number 3, p. 48. 